\title{
Avaliação bacteriológica das águas de bebedouros do campus da Universidade Estadual de Londrina - PR
}

\author{
Bacteriological evaluation of drinking fountains water at campus of \\ Universidade Estadual de Londrina - PR
}

\author{
Bruna Mara Silva Seco ${ }^{1}$, Tatiane das Neves Burgos², Jacinta Sanchez Pelayo ${ }^{3}$
}

\section{Resumo}

As águas de abastecimento são de grande importância na veiculação de microrganismos patogênicos visto que, durante sua distribuição, pode ocorrer contaminação por matéria fecal. As principais bactérias utilizadas como indicadores de poluição na água são os coliformes totais e coliformes termotolerantes, entre eles Escherichia coli podendo ser usado como indicador de poluição fecal. Segundo a portaria n ${ }^{\circ}$ 2914/2011 da ANVISA (Ministério da Saúde) entende-se por água potável, a água de consumo humano cujos parâmetros microbiológicos, físicos, químicos e radioativos atendam ao padrão de potabilidade que não ofereça riscos a saúde. Este trabalho teve como finalidade avaliar as condições bacteriológica, cloro residual e $\mathrm{pH}$ das amostras de água dos bebedouros do campus da Universidade Estadual de Londrina (UEL) no ano de 2011. Coliformes totais e E. coli foram analisados, através da técnica de Colilert em dezenove amostras e foram priorizados locais nos quais ocorre maior índice de pessoas com acesso aos bebedouros. Das amostras analisadas nenhuma apresentou contaminação por coliformes totais ou E. coli. Em relação a $\mathrm{pH}$ e cloro residual, todas as amostras estavam de acordo com a resolução da ANVISA. Entretanto, é importante manter um programa de monitoramento da qualidade bacteriológica da água consumida nos bebedouros do campus da UEL, uma vez que se esta estiver contaminada apresenta riscos à saúde tanto dos alunos como dos funcionários.

Palavras-chave: Água de bebedouro. Coliformes totais. Escherichia coli.

\begin{abstract}
The water supply is an important source for transmition of pathogenic microorganisms, since during the distribution fecal pollution may occur. Thermotolerant and total coliforms are the main groups of bacteria used as indicator of pollution and Escherichia coli is the main bacterium used as a parameter of fecal pollution. According to ANVISA resolution $N^{\circ} 2914 / 2011$ (Ministry of Health), a safe drinking water, for human consumption, the water presenting microbiological, physical, chemical and radioactive standards, safe to human health. The aim of this study was evaluate bacteriological conditions, residual chlorine and $\mathrm{pH}$ of water samples, collected from drinking fountains at the Campus of Universidade Estadual de Londrina (UEL) during 2011. Nineteen samples were analyzed for the presence of total
\end{abstract}

${ }^{1}$ Graduanda do curso de Ciências Biológicas, Departamento de Microbiologia, Laboratório de Bacteriologia, Universidade Estadual de Londrina, Brasil. E-mail: bruna_seco@hotmail.com.

${ }^{2}$ Mestranda do Programa de Pós graduação em Microbiologia, Departamento de Microbiologia, Laboratório de Bacteriologia, Universidade Estadual de Londrina, Brasil. E-mail: tatianeburgos@hotmail.com.

${ }^{3}$ Professora Doutora em Microbiologia do Departamento de Microbiologia, Laboratório de Bacteriologia; Universidade Estadual de Londrina, Brasil. Contato principal para correspondência. E-mail: jspelayo@gmail.com. 
coliforms and E. coli by Colilert technique, points more frequently used by people were selected. The results showed no contamination by E. coli or total coliforms. Values for residual chlorine and $\mathrm{pH}$ were in accordance to ANVISA resolution. However, monitoring program for evaluating bacteriological quality of water from drinking fountains is important to avoid contamination of bacteria which could be a risk for the health of students and employees of UEL.

Keywords: Drinking fountains. Total coliforms. Escherichia coli.

\section{Introdução}

A água é o mais importante recurso natural do planeta, indispensável a todos os seres vivos, constituindo insumo essencial a preservação da vida. A água é ingerida pelo homem em maior quantidade que todos os outros alimentos reunidos. Esse contato com a água justifica e explica a facilidade com que parasitas macroscópicos e microscópicos atingem o homem e nele se desenvolvem, quando outros fatores coadjuvantes são favoráveis à sua sobrevida, desenvolvimento ou multiplicação (CABRAL, 2010; CARVALHO; RECCO PIMENTEL, 2007).

As águas de abastecimento são de grande importância na veiculação de microrganismos patogênicos visto que, durante sua distribuição, poderá ocorrer contaminação por matéria fecal (HLAVSA et al., 2011). No Brasil, a portaria $n^{\circ}$ 2914/2011 do Ministério da Saúde estabelece, entre outros parâmetros, a análise de coliformes totais, termotolerantes ou Escherichia coli e de bactérias heterotróficas para análise de água para consumo humano, em toda e qualquer situação, incluindo fontes individuais, como poços, minas e nascentes (BRASIL, 2011).

Segundo a Portaria n ${ }^{0}$. 2914/2011, o sistema de abastecimento de água para consumo humano é composto por instalações providas de conjuntos de obras civis, materiais e equipamentos destinados à produção e a distribuição canalizada de água potável para populações, sob a responsabilidade do poder publico, mesmo que administrada em regime de concessão ou permissão. A água potável deve apresentar ausência de coliformes termotolerantes ou E. coli $\mathrm{em} 100 \mathrm{~mL}$ de amostra e ausência de bactéria do grupo coliformes totais em $100 \mathrm{~mL}$. De acordo com essa portaria, entende-se por água potável, a água de consumo humano cujos parâmetros microbiológicos, físicos, químicos e radioativos atendam ao padrão de potabilidade que não ofereça riscos à saúde (BRASIL, 2011).

As doenças de veiculação hídrica compreendem uma gama variada de patologias gastrintestinais causadas por bactérias, protozoários e vírus que resulta em ônus elevado para os países principalmente em desenvolvimento, onde seus efeitos são contundentes para a saúde pública (GERMANO; GERMANO, 2001; HLAVSA et al., 2011).

De acordo com os dados da Organização Mundial de Saúde (OMS) 80\% das doenças nos países em desenvolvimento são causadas pela água contaminada (COELHO et al., 2007). Aproximadamente 15 milhões de crianças menores que cinco anos morrem por ano por deficiência ou falta de um sistema adequado de abastecimento de água e esgoto (FERNANDEZ; SANTOS, 2007).

Assim, o objetivo do presente trabalho foi avaliar a qualidade bacteriológica da água e físicoquímica, disponível para consumo em bebedouros do campus universitário localizado em Londrina, PR., no ano de 2011. 


\section{Material e Métodos}

Amostragem

Avaliou-se o perfil bacteriológico, cloro residual e pH das amostras de água de 19 bebedouros da
Universidade Estadual de Londrina (UEL). As coletas foram realizadas no mês de setembro de 2011, abrangendo as unidades situadas no campus universitário, onde havia a concentração de um maior número de alunos (Tabela 1 ).

Tabela 1 - Local de coleta de amostras de água dos bebedouros da UEL-2011.

\begin{tabular}{|c|c|c|}
\hline Amostra & Identificação & Local da coleta \\
\hline 1 & CCB 201 & Centro de Ciências Biológicas - sala 201 \\
\hline 2 & CCB 202 & Centro de Ciências Biológicas - sala 202 \\
\hline 3 & $\mathrm{CCB} \mathrm{BIO}$ & Centro de Ciências Biológicas - corredor \\
\hline 4 & ANFI MORFO & Anfiteatro de Morfologia \\
\hline 5 & M ESTUDANTIL & Moradia Estudantil \\
\hline 6 & RU DENTRO & Restaurante Universitário - Dentro \\
\hline 7 & RU FORA & Restaurante Universitário - Fora \\
\hline 8 & BIB CIMA & Biblioteca Central - Andar de cima \\
\hline 9 & BIB BAIXO & Biblioteca Central - Andar de baixo \\
\hline 10 & PROGRAD & Pró - reitoria de Graduação \\
\hline 11 & CCH ANFI. & Anfiteatro do Centro de Ciências Humanas \\
\hline 12 & CESA ANFI. & Anfiteatro do Centro de Estudos Sociais Aplicados \\
\hline 13 & CCA TAM & Centro de Ciências Agrárias - Tecnologia de Alimentos \\
\hline 14 & HV. & Hospital Veterinário \\
\hline 15 & CECA & Centro de Educação, Comunicação e Artes \\
\hline 16 & $\mathrm{CCE}$ & Centro de Ciências Exatas \\
\hline 17 & CEFE & Centro Esportivo de Educação Física \\
\hline 18 & CTU & Centro de Tecnologia e Urbanismo \\
\hline 19 & ANATOMIA & Museu de Anatomia \\
\hline
\end{tabular}

Fonte: Autores 


\section{Coleta da Amostras}

Para a coleta das amostras dos bebedouros a água foi escoada por 1 minuto e após esse procedimento foram colhidas assepticamente em frascos estéreis acondicionados em caixas isotérmicas e transportadas para o Laboratório de Bacteriologia da UEL. As amostras foram conservadas a $4^{\circ} \mathrm{C}$ e analisadas em um período menor que 6 horas (AMERICAN PUBLIC ASSOCIATION, 2004).

\section{Metodologia}

Os parâmetros de qualidade utilizados para análise foram baseados na Portaria $n^{\circ} 2914$ do Ministério da Saúde (BRASIL, 2011), que define que a água para consumo humano deve ser livre de E. coli ou coliformes termotolerantes e coliformes totais em $100 \mathrm{~mL}$ de amostra e por tratar-se de bebedouros, livre de cloro. $\mathrm{O} \mathrm{pH}$ deve ficar na faixa de $6,0-9,0$.

Para a análise bacteriológica da água, utilizouse a técnica do substrato cromogênico Colilert (SOVEREIGN - BR), um método qualitativo e quantitativo que permite determinar o número mais provável (NMP) de coliformes totais e E. coli (AMERICAN PUBLIC ASSOCIATION, 2004; BRASIL, 2011). A técnica se baseia em reações de substratos enzimáticos onde os coliformes totais utilizam a enzima $\beta$-galactosidase para metabolizar o indicador de nutriente o-nitrofenil- $\beta$-Dgalactopiranosídeo (ONPG) adquirindo coloração amarela. E. coli utiliza a enzima $\beta$-glucuronidase para metabolizar o indicador 4-metil-umbeliferil (MUG) e desenvolver fluorescência sobre a luz ultravioleta. Foi retirada uma alíquota de $100 \mathrm{~mL}$ e homogeneizada com uma ampola do substrato Colilert, em um frasco estéril. Homogeneizou-se e transferiu para a cartela Quanti-Tray (WP2000) com 49 células grandes e 48 células pequenas. A cartela foi selada, utilizando a seladora Quanti Tray Sealer (IDEXX/SOVEREIGN - BR). As cartelas foram incubadas a $35^{\circ} \mathrm{C}$ por 24 horas. Para realizar a leitura foi utilizada uma lâmpada ultravioleta
Phillips de 365nm.

Consideraram-se positivo o teste para coliformes totais as células da cartela que apresentavam a coloração amarela e para E. coli as células que apresentavam florescência sobre a luz ultravioleta. O resultado foi avaliado utilizando uma tabela de NMP, no qual se relaciona a quantidade de células grandes que apresentam resultado positivo com a quantidade de células pequenas também positivas. O número resultante é o NMP em 100 mL na água.

Para a detecção do cloro residual, utilizou-se o comparador colorimétrico modelo DHL-2000 da DELLAB de Araraquara-SP. Para a medição, coloca-se a amostra de água numa cuba de $5 \mathrm{~mL}$, depois é colocado o reagente DPD (orto-Tolidina) em pó. Essa cubeta foi então introduzida no orifício direito do comparador que foi comparado com outra cuba com água destilada no orifício esquerdo. Para dosar a quantidade de cloro gira-se o disco colorimétrico para comparar a cor apresentada na cubeta com a amostra de água com as cores contidas no disco. A medida é apresentada em $\mathrm{mg} / \mathrm{L}$ de cloro residual.

Para medir o $\mathrm{pH}$ das amostras foi utilizado o aparelho HI 2221 Calibration Check pH/ORP Meter da HANNA Instruments. Foi realizada a calibração do aparelho em dois pontos sendo o primeiro de $\mathrm{pH}$ 4 e o segundo de $\mathrm{pH}$ 7. Após isto foi realizada a leitura das amostras.

A partir dos resultados das 19 amostras, traçouse o perfil bacteriológico das águas dos bebedouros.

\section{Resultados e Discussão}

Todas as 19 amostras de água colhidas dos bebedouros do campus da UEL foram negativas para coliformes totais e E. coli. $\mathrm{O} \mathrm{pH}$ de todas as amostras estavam dentro das normas estabelecidas e nenhuma das amostras apresentou cloro residual, mostrando-se próprias para consumo (Tabela 2). 
Tabela 2 - Resultados da análise das águas de bebedouros da UEL.

\begin{tabular}{|c|c|c|c|c|}
\hline \multirow[b]{2}{*}{ Amostra } & \multirow[b]{2}{*}{ Totais } & \multicolumn{2}{|c|}{ Coliformes } & \multirow[b]{2}{*}{ Cloro residual } \\
\hline & & E. coli & pH & \\
\hline 1 & Ausente & Ausente & 6,54 & $0 \mathrm{mg} / \mathrm{L}$ \\
\hline 2 & Ausente & Ausente & 6,87 & $0 \mathrm{mg} / \mathrm{L}$ \\
\hline 3 & Ausente & Ausente & 6,63 & $0 \mathrm{mg} / \mathrm{L}$ \\
\hline 4 & Ausente & Ausente & 6,29 & $0 \mathrm{mg} / \mathrm{L}$ \\
\hline 5 & Ausente & Ausente & 6,29 & $0 \mathrm{mg} / \mathrm{L}$ \\
\hline 6 & Ausente & Ausente & 6,45 & $0 \mathrm{mg} / \mathrm{L}$ \\
\hline 7 & Ausente & Ausente & 6,63 & $0 \mathrm{mg} / \mathrm{L}$ \\
\hline 8 & Ausente & Ausente & 6,24 & $0 \mathrm{mg} / \mathrm{L}$ \\
\hline 9 & Ausente & Ausente & 6,18 & $0 \mathrm{mg} / \mathrm{L}$ \\
\hline 10 & Ausente & Ausente & 6,22 & $0 \mathrm{mg} / \mathrm{L}$ \\
\hline 11 & Ausente & Ausente & 6,11 & $0 \mathrm{mg} / \mathrm{L}$ \\
\hline 12 & Ausente & Ausente & 6,35 & $0 \mathrm{mg} / \mathrm{L}$ \\
\hline 13 & Ausente & Ausente & 6,31 & $0 \mathrm{mg} / \mathrm{L}$ \\
\hline 14 & Ausente & Ausente & 6,39 & $0 \mathrm{mg} / \mathrm{L}$ \\
\hline 15 & Ausente & Ausente & 6,24 & $0 \mathrm{mg} / \mathrm{L}$ \\
\hline 16 & Ausente & Ausente & 6,15 & $0 \mathrm{mg} / \mathrm{L}$ \\
\hline 17 & Ausente & Ausente & 6,17 & $0 \mathrm{mg} / \mathrm{L}$ \\
\hline 18 & Ausente & Ausente & 6,95 & $0 \mathrm{mg} / \mathrm{L}$ \\
\hline 19 & Ausente & Ausente & 6,14 & $0 \mathrm{mg} / \mathrm{L}$ \\
\hline
\end{tabular}

Fonte: Autores

Em Minas Gerais foram analisadas amostras de água coletadas de 20 bebedouros do Campus Universitário de Ipatinga e nenhuma apresentou coliformes totais e E. coli (BARBOSA et al. 2009).
Oliveira; Terra (2004), em Uberaba-MG, os resultados apresentados mostraram que, em algumas amostras, houve algum tipo de contaminação por coliformes. Os bebedouros que tiveram menor 
número de contaminação foram os abastecidos por água que não passaram por um reservatório existente na Faculdade.

Segundo Zulpo et al. (2006), ao estudarem a qualidade microbiológica da água consumida nos bebedouros da Universidade Estadual do CentroOeste, Guarapuava - PR, concluíram que, dentro das 47 amostras analisadas, $8,5 \%$ foram positivas para coliformes totais e $2 \%$ para coliformes termotolerantes.

Em Diamantina - MG, foram analisadas amostras de águas de bebedouros de dois campus da UFVJM, sendo um do campus geral e outro campus Presidente Juscelino Kubitschek. Das amostras de água coletadas dos 14 bebedouros, nenhuma apresentou coliformes totais ou fecais, porém foram encontrados fungos em algumas das amostras (DANTAS, et al. 2010).

Em Recife, Siqueira et al. (2010) analisaram amostras de água de 40 estabelecimentos de alimentos localizados entorno da Universidade Federal Rural de Pernambuco (UFRPE) e da Universidade Federal de Pernambuco (UFPE). Dentre as amostras estudadas, 62,5\% apresentaram coliformes totais e $42,5 \%$ apresentaram coliformes termotolerantes.

Dentre todos os dados apresentados existe uma discrepância entre as unidades estudadas, indicando que a contaminação pode ser devido aos métodos de conservação e armazenamento da água e sua posterior distribuição e manutenção dos filtros dos bebedouros.

Comparando-se os resultados obtidos neste trabalho com outros estudos realizados com o objetivo de avaliar a qualidade microbiológica de águas de bebedouros, em universidades e outras instituições, observa-se que, as amostras avaliadas nos bebedouros do campus da UEL apresentaram qualidade bacteriológica e físico-química satisfatória, o que não descarta a necessidade de um acompanhamento constante da qualidade da água disponível nos bebedouros do campus. Desse modo, as contaminações por possíveis bactérias patogênicas poderão ser eliminadas, e manterse-á, assim, a boa qualidade da água para consumo humano, para serem evitados riscos à saúde.

\section{Conclusão}

A partir da análise feita no Laboratório de Bacteriologia da Universidade Estadual de Londrina, pode-se concluir que em todos os locais de coleta de água de bebedouros obedeceram aos padrões de qualidade exigidos pela portaria ${ }^{\circ} 2914$ do Ministério da Saúde, sendo, portanto águas apropriadas para o consumo. Isso se deve ao fato das boas condições da manutenção dos reservatórios de água da universidade, bem como, da manutenção dos bebedouros, e, consequentemente, não se coloca em risco a saúde dos alunos e funcionários que utilizam essa água.

Faz-se necessário um monitoramento e manutenção constante da água e dos bebedouros em relação ao controle microbiológico, podendo assim garantir uma água de qualidade a todos que utilizarem os bebedouros deste campus universitário.

\section{Agradecimentos}

À UEL e a Secretaria de Estado da Saúde do Paraná (SESA) pelo apoio financeiro e a CAPES pelo auxílio da bolsa de estudo.

\section{Referências}

AMERICAN PUBLIC HEALTH ASSOCIATION. Standard methods for the examination of water and wastewater. 21. ed. Washington, 2004.

BARBOSA, D. A.; LAGE, M. M.; BADARÓ, A. C. L. Qualidade microbiológica da água dos bebedouros de um campus universitário de Ipatinga, Minas Gerais. Revista 
Digital de Nutrição, Ipatinga. v. 3, n. 5, p. 505-517, 2009.

BRASIL. Ministério da Saúde. Secretaria de Vigilância Sanitária. Portaria no 2914 de 12 de Dezembro de 2011. Diário Oficial da União, Brasília, 2011.

CABRAL, J. P. S. Water microbiology: bacterial pathogens and water. International Journal of Environmental Research and Public Health, Basel, v. 7, p. 3657-3703, 2010

CARVALHO, H. F.; RECCO-PIMENTEL, S. M. Moléculas importantes para a compreensão da célula e do seu funcionamento. In: Paulo: Manole, 2007. p. 7-28.

COELHO, D. A.; SILVA, P. M. F.; VEIGA, S. M. O. M.; FIORINI, J. E. Avaliação da qualidade microbiológica de águas minerais comercializadas em supermercados da cidade de Alfenas, MG. Revista Higiene Alimentar, São Paulo, v. 21, n. 151, p. 88-92, 2007.

DANTAS, A. K. D.; SOUZA. C.; FERREIRA, M. S.; ANRADE, M. A.; ANDRADE, D.; WATANABE, E. Qualidade microbiológica da água de bebedouros destinada ao consumo humano. Revista Biociências UNITAU, Taubaté, v. 16, n. 2, p. 132-138, 2010.

FERNANDEZ, A. T.; SANTOS, V. C. Avaliação de parâmetros físico-químicos e microbiológicos da água de abastecimento escolar, no município de Silva Jardim, RJ. Revista Higiene Alimentar, São Paulo, v. 21, n. 154, p. 93-98, 2007.

GERMANO, P. M. L.; GERMANO, M. I. S. Higiene e vigilância sanitária de alimentos. São Paulo: Varela, 2001.

HLAVSA, M. C.; ROBERTS, V. A.; ANDERSON, A. R.; HILL, V. R.; KAHLER, A. M.; ORR, M.; GARRISON, L. E.; HICKS, L. A.; NEWTON, A.; HILBORN, E. D.; WADE, T. J.; BEACH, M. J.; YODER. J. S. Centers For disease control and prevention: surveillance for waterborne disease outbreaks and other health events associated with recreational water - United States, 20072008. Morbidity Mortality Weekly Report, Atlanta, v. 60, n. 12, p. 1-32, 2011.

OliveIRA, A. C. S.; TERRA, A. P. S. Avaliação microbiológica das águas dos bebedouros do campus I da faculdade de medicina do Triângulo Mineiro, em relação à presença de coliformes totais e fecais. Revista da Sociedade Brasileira de Medicina Tropical, Rio de Janeiro, v. 37, n. 3, p. 285-286, 2004.

SIQUEIRA, L. P.; SHINOHARA, N. K. S.; LIMA, R. M. T.; PAIVA, J. E.; FILHO, J. L. L.; CARVALHO, I. T. Avaliação microbiológica da água de consumo empregada em unidades de alimentação. Ciência \& Saúde Coletiva, Rio de Janeiro, v. 15, n. 1, p. 63-66, 2010.
ZULPO, D. L. et al. Avaliação microbiológica da água consumida nos bebedouros da universidade estadual do Centro-Oeste, Guarapuava, Paraná, Brasil. Semina: Ciências Agrárias, Londrina, v. 27, n. 1, p. 107-110, 2006.
Recebido em 19 de dezembro de 2011. Aceito em 23 de julho de 2012. 
